\title{
Current challenges and strategies in management and prevention of stroke
}

News

\section{Know stroke! Know the signs! Act in time!}

Stroke is Lack of blood flow to the brain caused by a clot or rupture of a blood vessel. Without oxygen, brain cells begin to die and death resulted in permanent disability. It is the public health challenge of the 21 st century and also named as Cerebrovascular accident/ disease (CVA), cerebral infarction, cerebral hemorrhage or brain at-tack.

Although stroke is easily preventable, it remains the second leading cause of death and a first leading cause of acquired disability in adults worldwide currently. Over $75 \%$ of cases occur after $65 y$ ears of age and incidence of stoke is rising in many developing countries because of the adoption of less healthy lifestyles. In USA on aver-age, every 53 seconds, someone experiences a stroke and every 3.1 minutes someone dies of a stroke. In UK it strikes every $3 \frac{1}{2}$ minutes, yet many people remain unaware of the most common signs. Studies in Ethiopia reveal that there is an increasing episode and $6.5 \%$ of admissions were due to stroke.

Stroke does not discriminate. It affects people of all ages, ethnic groups and backgrounds. The estimated direct and indirect cost of stroke is 73.7billion in 2013. Of all cardiovascular disease clinical entities, none is more strongly linked to hypertension than stroke. Hypertension, previous Transient ischemic attack, smoking, diabetes mellitus, atrial fibrillation, cardiovascular diseases, heart failure, old age, alcohol intake and others were known risk factors for stroke. Recent developments studies indicate that psychological stress, poor thinking skills, longer working hours, alpha-blockers in older increases risk of stroke and other heart disease.

Stroke is the public health challenge of the 21st century!!

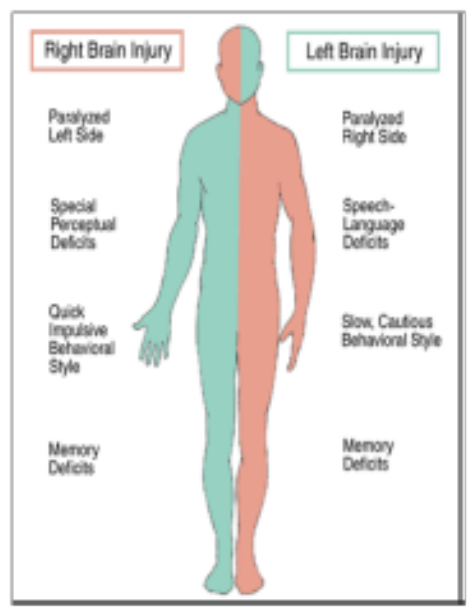

Strokes occur in the brain and affect the opposite side of the body. In the left half of the brain Stroke can cause:

\section{Speech and language problems}

The stroke survivor may have trouble speaking or understanding others.
Volume 9 Issue 3 - 2019

\author{
Ginenus Fekadu \\ Department of Pharmacy, Institute of Health Sciences, Wollega \\ University, Ethiopia
}

Correspondence: Ginenus Fekadu, Department of Pharmacy, Institute of Health Sciences, Wollega University, Nekemte, Ethiopia, Tel + 25I(0)9l7I37I45; + 25I(0)9l7733383, Email take828pharm@gmail.com, ginenus@wollegauniversity.edu.et

Received: February 05, 2019 | Published: May 13, 2019

\section{Slow and cautious behavior}

The stroke survivor may need a lot of help to complete tasks.

\section{Memory problems}

The stroke survivor may not remember what she did ten minutes ago or she may have a hard time learning new things.

\section{Recognize the symptoms of a stroke}

3 Simple Questions

i. Ask the person to smile

ii. Ask the person to raise both arms

iii. Ask the person to say a simple sentence "I am in Nekemte"

\section{Management of stroke}

General management of patients with stroke

The goal of treating stroke is to reduce the ongoing neurologic injury and decrease mortality and long-term disability. It also targeted to prevent complications secondary to immobility and neurologic dysfunction, and preventing stroke recurrence. Minimizing the volume of brain that is irreversibly damaged and handicap of the patients through rehabilitation were other prioritized areas of the treatment.

\section{Currently available technologies for diagnosis of stroke}

1. Computed Tomography (CT)

2. Magnetic Resonance Imaging (MRI)

3. Cerebral Angiography: identify responsible blood vessel

4. Electrocardiogram (ECG): underlying heart conditions

5. Echocardiogram: blood clot from heart

6. Carotid Duplex: carotid artery stenosis

7. Heart monitors, blood work and many more tests!! 


\section{Management of stroke is based on type of stroke \\ Ischemic stroke}

A blood vessel becomes blocked and the blood supply to that part of your brain is blocked. There are two types of ischemic stroke constituting of thrombotic stroke and embolic stroke.
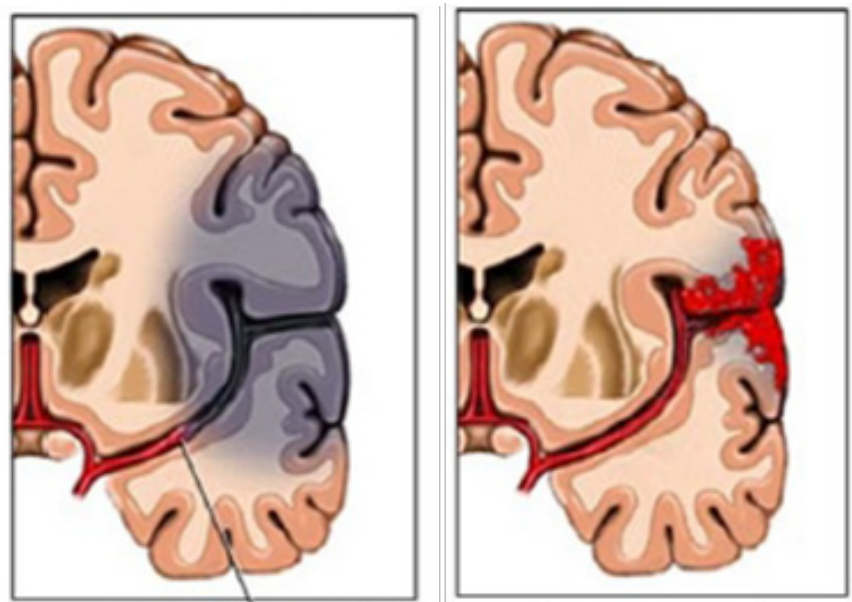

\section{A clot blocks blood flow Bleeding occurs inside or} to an area of the brain around brain tissue

\section{Treatment}

Acute treatment the first line drug is t-PA (Alteplase) $0.9 \mathrm{mg} / \mathrm{kg}$ IV (maximum 90mg) over 1hour in selected patients within 3hours of onset or $0.9 \mathrm{mg} / \mathrm{kg}$ IV (maximum $90 \mathrm{mg}$ ) over 1hour between 3 and 4.5hours of on-set. Rapid administration of intravenous recombinant tissue type plasminogen activator (r-tPA) to appropriate patients remains the mainstay of early treatment of acute ischemic stroke. Timely restoration of blood flow in ischemic stroke patientsis effective in reducing patients is effective in reducing long-term morbidity. For patients who meet national and international eligibility guide-lines, intravenous rt-PA improves functional outcomes at 3 to 6 months when given within 4.5 hours of ischemic stroke on-set and should be administered. The guidelines highlight that, once the decision to administer rtPA is made, treatment should begin as rapidly as possible. ${ }^{1,2}$

The other drug widely studied for the treatment of acute ischemic stroke is aspirin $160-325 \mathrm{mg} /$ day started between $24-48$ hours after comple-tion of alteplase reduces longterm disability and death. But it should never be given within 24hours of the administration of tPA because it can increase the risk of bleeding in such patients.

Additionally there are different devices as non-pharmacological treatments currently approved by FDA. One of FDA approved device is Merci Retriever. It cor kscr ew-like device is an option for patients ineligible for t-PA treatment. The device is threaded through a catheter up through the body to the clot in the brain. The clot is then removed, restoring the blood flow to the affected area of the brain. The other device is the Penum-bra System. It is a new embolectomy device specifically designed to remove the thrombus in acute ischemic stroke secondary to large vessel thromboembolism.

\section{Secondary prevention}

For noncardioembolic antiplatelet therapy is the cornerstone of antithrombotic therapy for the secondary prevention of ischemic stroke and should be used in noncardioembolic strokes. As-pirin 50 $325 \mathrm{mg}$ daily (is best stud-ied), clopidogrel (75mg daily), and extended release dipyridamole (200mg BID)-ASA (25mg) are considered firstline antiplatelet agents.

Cilostazol is also a recommended first-line antiplatelet agent, but its use has been limited by a lack of data in other than Asian populations. In patients with atrial fibrillation and a presumed cardiac source of embolism, warfarin is the antithrombot-ic agent of first choice. In the European Atrial Fibrilla-tion Trial (EAFT), 669 patients were randomized to warfarin (INR=2.5 to 4), aspirin $300 \mathrm{mg}$ / day, or placebo. Patients in the placebo group experienced stroke, MI, or vascular death at a rate of $17 \%$ per year compared with $8 \%$ per year in the warfarin group and $15 \%$ per year in the ASA group. This represents a $53 \%$ reduction in risk with anticoagulation.

In addition to drugs there are also non pharmacologi-cal instruments and surgical procedures for embolic origin of ischemic stroke as secondary prevention. These include Carotid Endarterectomy and Angioplasty/Stents. American stroke association on 2015 passed new recommendation on the stents and angioplasty. "Angioplasty and stinting of proximal cervical atherosclerotic stenosis or complete occlusion at the time of thrombectomy may be considered, but the usefulness is unknown thus future randomized studies are needed"

In addition to treating ischemic stroke, baseline risk factors and cause like hypertension and dispilipidemia should be treated with appropriate medications.

\section{Current challenges with treatment}

Despite its effectiveness in improving neurological outcomes, many pa-tients with ischemic stroke are not treated with recombinant tissue plasminogen activator (rt-PA), because they arrive late or because of delays in assessment/administration of IV t- PA. But in developing countries t-PA and newly approved devices are unaffordable and there is inappropriate treatment due to misdiagnosis due to lack of appropriate diagnostic agents.

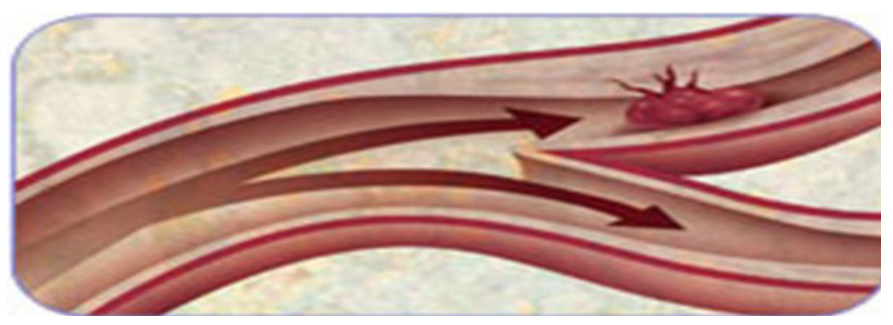

\section{Hemorrhagic stroke}

Occurs when a small blood vessel in the brain becomes weak and ruptures. It includes bleeding around brain and bleeding into brain. Based on the manifestations and causes there 3 types of hemorrhagic stroke. Subarachnoid hemorrhage (SAH), intracerebral hemorrhage (ICH) and subdural hematomas.

\section{Treatment}

Treatment for Intracerebral hemorrhage currently their e is no 
standard pharmacologic strategies available. Management involves a combination of medical and surgical interventions. Use of antipyretic medications to lower body temperature to normothermia in febrile patients with is necessary. Patients may require external ventricular drainage (EVD) if there is intraventricular blood and evolving hydrocephlus (enlargement of the ventricles). When ICH occurs in a patient on warfarin (INR $>1.3$ ), rapid reversal of anticoagulation to prevent expansion and allow surgical intervention is recommended with intravenous vitamin $\mathrm{K}$, hemostatic agents and prothrombincomplex concentrate (PCC). High doses (10 to $20 \mathrm{mg}$ ) of intravenous vitamin $\mathrm{K}$ can fully reverse warfarininduced anti-coagulation.

Treatment of subarachnoid hem-orrhage goes to initial supportive treatments like bed rest and analgesic. In addition blood pressure control and oral ni-modipine $60 \mathrm{mg}$ every 4 hours for 21 days is necessary. If an aneurysm is found by angiography, endovascular coiling or clipping via a craniotomy should be performed to reduce the risk of rebreeding. Vasospasm of the cerebral vasculature is thought to be responsible for the delayed ischemia and occurs between 4 and 21 days after the bleeding.

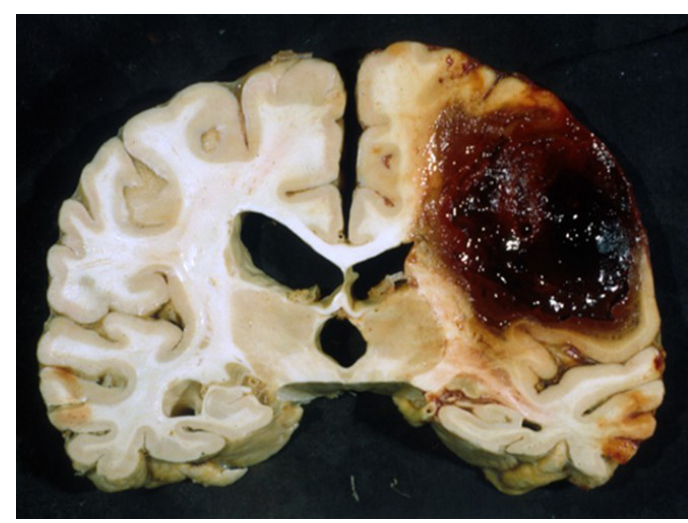

\section{Hemorrhagic stroke}

The essentials of the treatment protocol for Alteplase (t-PA)

a. stroke team activation

b. onset of symptoms within 3hours

c. CT scan to rule out hemorrhage

d. avoiding anticoagulant or antiplatelet therapy for 24hours, and Monitoring the patient closely for response and hemorrhage

Latest meta-analysis of randomized trial Research of 2015 revealed that "Irrespective of age or stroke severity, and despite an increased risk of fatal intracranial hemorrhage during the first few days after treatment, Alteplase significantly improves the overall odds of a good stroke outcome when delivered within $4 \cdot 5 \mathrm{~h}$ of stroke onset, with earlier treatment associated with bigger proportional benefits." ${ }^{3}$

\section{Challenges of stroke managements in developing countries including Ethiopia}

Virtually all of the excess morbidity and mortality that occur as a consequence of stroke and other neurological disorders in developing counties result from scarcities of resources.
The first resource deficit is Human Resources. Countries in developing counties like Ethiopia do not have sufficient qualified staff in the clinical neurosciences (neurologists, neurosurgeons, psychiatrists)

The other problem is lack of diagnostic facilities (instrumentation). There are no sophisticated diagnostic agents like CT scan, MRI, cerebral angiography, ECG, carotid duplex and others. The most important diagnostic measures are through interviews and by the usual clinical examination, looking for signs and symptoms of disturbed neurologic functions this could lead to misdiagnosis affecting the treatment approach. However accurate diagnosis and management often re-quires diagnostic means that are usually found in well equipped hospitals and facilities.

In addition most drugs for stroke like tissue plasminogen activator (t-PA) are cost which are unaffordable by most patients and countries in developing countries. Other facilities like System for maintaining medical records, referral facilities are very poor in developing countries like Ethiopia.

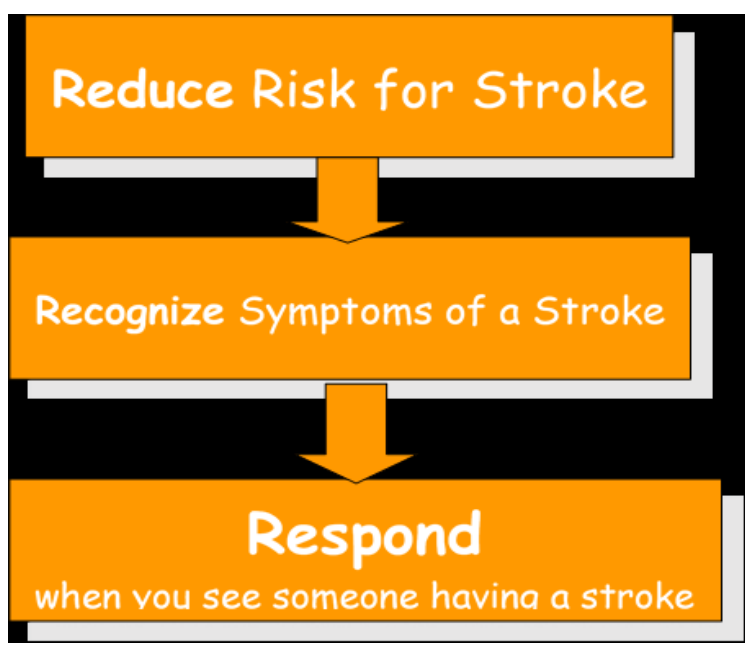

Be Stroke Smart: The 3 R's of Stroke

"Together, with the best possi-ble adherence to currently ex-is $t$ ing $r$ e commendat ions and with novel options that could become available in the future; the golden hour of stroke could be used much more efficiently than it is used today"

\section{Key issues in preventing recurrent stroke}

High blood pressure can put a person at risk for having another stroke. So can depression. According to a new study, though, the risk to more than 80 percent for stroke survivors experiencing both hypertension and depression. Taking these precautions to en-sure that susceptible people should not be fall into either category. The study found that, in the first four years after a stroke or heart attack, depressed survivors with high blood pressure were 83 percent more likely to have another stroke or heart at-tack, heart failure, or die due to heart disease than were their counterparts who had normal blood pressure and were not depressed. It is such a significant percentage that the study suggests doctors should not only closely monitor stroke survivors' blood pressure but also screen them for depression. 


\section{Other study proven strategies in primary prevention of stroke}

Different studies revealed that more than $80 \%$ of stroke could be prevented. This could be possible by creating awareness to community in life style modification and behavioral change by knowing reality behind the stroke. There are different recommendations and advices to different peoples. Some of could be:

a. Stopping tobacco use, or reducing the amount smoked, or not start the habit

b. becoming physically active: reducing body mass index, waisthip ratio/waist circumference

c. Drinking the alcohol so in moderation.

d. Managing stress

e. Knowing one's own cholesterol number: lowering blood cholesterol and low density lipoprotein cholesterol (LDLcholesterol)

f. Eating a healthy diet: Enjoying lower sodium (salt) and lowering fat diet.

g. Controlling glycemia

h. Taking antiplatelet therapy when necessary.

i. If one experiences any stroke symptoms, seeking immediate medical attention are the bench mark of stroke prevention strategies.

Challenges: Why people don't recognize and respond to symptoms
a. Don't recognize symptoms
b. Denial
c. Think nothing can be done
d. Worry about cost
e. Think symptoms will go away
f. Fear or don't trust hospitals

\section{Pay Attention to these symptoms}

Transient Ischemic attack should not be ignored

a. More than $1 / 3$ of people will go on to have an actual stroke

b. $5 \%$ of strokes will occur within 1 month of the TIA or first stroke

c. $12 \%$ will occur within 1 year

d. $20 \%$ will occur within 2 years

e. $25 \%$ will occur within 3years

\section{Current rehabilitation processes of patients} with stroke

The rehabilitation starts by preventing, recognizing, and managing co morbid illness and medical complications. Training for maximum independence and facilitating maximum psychosocial coping and adaptation by patient and family is one of the key issues. In addition to this prevention of secondary disability by promoting community reintegration, including resumption of home, family, recreational, and vocational activities are necessary. Enhancing quality of life in view of residual disability; and preventing recurrent stroke and other vascular conditions such as myocardial infarction that occur with increased frequency in patients with stroke are also recommended.

\section{Future perspectives of stroke prevention and management strategies especially in Ethiopia}

Creating a community education outreach team with public relations, volunteers, and hospital educators is necessary in minimizing current severity of stroke. The issue is government concern and policy in provision of standardized instruments for stroke recognition and priority transport to the closest hospital with appropriate emergency stroke care. Primary prevention, early diagnosis and appropriate management of stroke should be improved by education of the pub-lic and healthcare professionals. As in developed countries F.A.S.T. (faces, arms, and speech, time) education to entire hospital and proposing a clear and specific action in response to stroke is mandatory.

\section{Perceptions of people affect the treatment because of having myths views which are not real-ly true like:}

a. Stroke is not preventable

b. Stroke cannot be treated

c. Stroke only strikes the elderly

d. Stroke happens in the heart

e. Stroke recovery ends after 6 months

\section{Management and prevention strategies of stroke: summary}

Management of stroke includes primary prevention, active management of the acute stroke phase, secondary prevention and rehabilitation. Hypertension, the single most important risk factor for stroke, should be actively man-aged; patients should be monitored regularly to ensure optimal control and to promote compliance with therapy. Early detection and management of atrial fibrillation as well as proactive management of modifiable risk factors such as smoking, diet (including salt in-take), alcohol intake and exercise has also been shown to greatly re-duce the risk of stroke.

Patients with ongoing symptoms suggestive of acute stroke should be advised to seek immediate hospital admission, in order to increase their chance of thrombolytic therapy if warranted. In addition to thrombolytic therapy, patient out-come in the acute phase is improved by multidisciplinary management in a stroke care unit, use of aspirin ( $\geq 24$ hours after thrombolysis) and early rehabilitation. Stroke patients are at increased risk of further strokes therefore they need to be actively managed with antihypertensive and lipid lowering therapies, and management of life-style factors; regular follow-up ensures optimal control and improves patient compliance Up to $30 \%$ of patients who experience a transient Ischemic attack (TIA) are at risk of developing an acute stroke within 30 days; therefore TIA patients require urgent assessment and aggressive management of risk factor. Primary prevention, early diagnosis and appropriate management of stroke can be improved by education of the public and healthcare professionals. ${ }^{4-35}$ 
Taking full responsibility, together we can save life's of millions from stroke!

\section{Acknowledgments}

None.

\section{Conflicts of interest}

Author declares there are no Conflicts of interest.

\section{References}

1. National Institute of Neurological Disorders and Stroke rt-PA Stroke Study Group. Tissue plasminogen activator for acute ischemic stroke. $N$ Engl J Med. 1995;333(24):1581-1587.

2. National Stroke Association. The Complete Guide to Stroke. 2013.

3. Emberson J, Lees KR, Lyden P, et al. Effects of intravenous thrombolysis with Alteplase for acute is-chemic stroke: ameta-analysis of individual patient data from ran-domized trials. The Lancet. 2014;384(9958):19291935.

4. AHA/ASA Guideline Focused Update on Acute Ischemic Stroke and Endovascular Treatment. 2015.

5. Yan LL, Li C, Chen J, et al. Prevention, management, and rehabilitation of stroke in low- and middle-income countries. eNeurological Sci. 2016;2:21-30

6. Feigin VL, Forouzanfar MH, Krishnamurthi R, et al. Global and regional burden of stroke during 1990-2010: findings from the Global Burden of Disease Study 2010. Lancet. 2014;383(9913):245-254.

7. Powers WJ, Rabinstein AA, Ackerson T, et al: Guidelines for the Early Management of Patients With Acute Ischemic Stroke: A Guideline for Healthcare Professionals From the American Heart Association/American Stroke Association. Stroke. 2018;49(3):e46-e110.

8. Brainin M, Teuschl Y, Kalra L. Acute treatment and long-term management of stroke in developing countries. Lancet Neurol. 2007;6(6):553-561.

9. Hohnloser SH, Duray GZ, Baber U, et al. Prevention of stroke in patients with atrial fibrillation: current strategies and future directions. European Heart Journal Supplements. 2008;10(Suppl H):H4-H10.

10. Lemogoum D, Degaute JP, Bovet P. Stroke Prevention, Treatment, and Rehabilitation in Sub-Saharan Africa. Am J Prev Med. 2005;29(5S1):95101.

11. Kolapo KO, Vento S. Stroke: a realistic approach to a growing problem in sub-Saharan Africa is urgently needed. Tropical medicine \& international health: TMIH. 2011;16(6):707-710.

12. Garbusinski Johanne $M$, van der Sande Marianne A.B, Bartholome Emmanuel J , Dramaix Michèle, Gaye Alieu, Coleman Rosalind, et al. Stroke Presentation and Outcome in Developing Countries. A Prospective Study in the Gambia. Stroke. 2005;36(7):1388-1393.

13. Lloyd-Sherlock Peter. Stroke in Developing Countries: Epidemiology, Impact and Policy Implications. Development Policy Review. 2010;28(6):693-709.

14. Refe Aurélie, Schmidta Chérif, Heroumb Didier, et al. Acute Ischemic Stroke (AIS) Patient Management in French Stroke Units and Impact Estimation of Thrombolysis on Care Pathways and Associated Costs. Cerebrovasc Dis. 2015;39:94-101.
15. http://www.americanheart.org/presenter.jhtml?identifier $=1200026$

16. Go AS, Mozaffarian D, Roger VL, et al. Heart Disease and Stroke Statistics-2014 Update: A Report From the American Heart Association. Circulation. 2014;129(3):e28-e292.

17. AHA/ASA Guideline, Focused Update on Acute Ischemic Stroke and Endovascular Treatment. 2015

18. Silberberg D, Katabira E. Disease and Mortality in Sub-Saharan Africa In: Dean T Jamison, Richard G Feachem, et al. editors, 2nd edn. World Bank. 2012.

19. Roth EJ. Medical rehabilitation of the stroke patient. Be Stroke Smart: National Stroke Association Newsletter. 2009;8:8.

20. Owolabi MO, Akarolo-Anthony S, Akinyemi R, et al. The burden of stroke in Africa: a glance at the present and a glimpse into the future. Cardiovasc $J$ Afr. 2015;26(2):S27-S38.

21. Acute and Preventative Treatments. American Stroke Association. 2007.

22. Impact of Stroke. American Stroke Association. 2007

23. Mozaffarian D, Benjamin EJ, Go AS, et al. Heart Disease and Stroke Statistics-2016 Update: A Report From the American Heart Association. Circulation. 2016;133(4):e38-e360.

24. Feigin VL, Krishnamurthi RV, Parmar P, et al. Update on the Global Burden of Ischemic and Hemorrhagic Stroke in 1990-2013: The GBD 2013 Study. Neuroepidemiology. 2015;45(3):161-176.

25. World Health Organization. Prevention of Cardiovascular Disease. Guidelines for assessment and management of cardiovascular risk. Geneva: World Health Organization (WHO); 2007.p. 86.

26. Fassbender K, Balucani C, Walter S, et al. Streamlining of prehospital stroke management: the golden hour. Lancet Neurol. 2013;12(6):585-596.

27. Kleindorfer D, Khoury J, Broderick JP, et al. Temporal Trends in Public Awareness of Stroke Warning Signs, Risk Factors, and Treatment. Stroke. 2009;40(7):2502-2506.

28. Kothari R, Sauerbeck L, JauchE, et al. Patients' awareness of stroke signs, symptoms and risk factors. Stroke. 1997;28(10):1871-1875.

29. Levitt MA, Dawkins R, Williams V, et al. Abbreviated educational session improves cranial computed tomography scan interpretations by emergency phsycians. Ann Emerg Med. 1997;30(5):616-621.

30. Alberts MJ, Bertels C, Dawson DV. An analysis of time of presentation after stroke. bamford JG, et al. Stroke: a practical guide to management [Table 15.2]. Oxford: blackwell Science; 2000.

31. Bernhardt J, Thuy MNT, Collier JM, et al. Very early versus delayed mobilisation after stroke. Cochrane Database Syst Rev. 2018;10:CD006187.

32. Management of patients with stroke: Rehabilitation, prevention and management of complications, and discharge planning A national clinical guideline. 2010 .

33. Changing Cardiovascular Health. National Cardiovascular Health Policy 2010-2019. Dept of Health \& Children 2010

34. Wang KL, Lip GY, Lin SJ, et al. Non-Vitamin K Antagonist Oral Anticoagulants for Stroke Prevention in Asian Patients with Nonvalvular Atrial Fibrillation: Meta-Analysis. Stroke. 2015;46(9):2555-2561.

35. Feigin Valery L, Norrving Bo, George Mary G, et al. Prevention of stroke: a strategic global imperative. Nat Rev Neurol. 2016;12(9):501-512. 